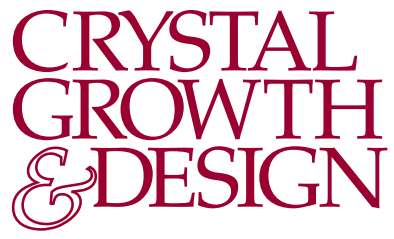

\title{
Ionic Cocrystals of Pharmaceutical Compounds: Sodium Complexes of Carbamazepine
}

\author{
3 Amanda R. Buist and Alan R. Kennedy* \\ 4 WESTCHEM, Department of Pure and Applied Chemistry, University of Strathclyde, 295 Cathedral Street, Glasgow G1 1XL
}

5 Scotland

6 S Supporting Information

7 ABSTRACT: Three inorganic cocrystal (ICC) forms of carbamazepine

8 (CBZ) have been synthesized, and their crystal structures are described. $\left[\mathrm{Na}(\mathrm{CBZ})_{4}(\mathrm{MeOH})\right][\mathrm{I}] \cdot \mathrm{H}_{2} \mathrm{O}, \quad\left[\mathrm{Na}(\mathrm{CBZ})_{5}\right]\left[\mathrm{I}_{3}\right]$, and $\left[\mathrm{Na}(\mathrm{CBZ})_{5}\right]-$ $\left[\mathrm{C}_{13} \mathrm{H}_{10} \mathrm{~N}\right]\left[\mathrm{IBr}_{2}\right]_{2}$ are the first $\mathrm{CBZ}$ structures that contain metal cations, and the latter example also contains acridinium, which is a known metabolite of CBZ. All three $\mathrm{Na}$ complexes have distorted square pyramidal $\mathrm{NaO}_{5}$ coordination geometries but different conformations of the four basal ligands and different hydrogen bonding interactions for the apical ligand. The hydrogen bonded synthons that have been identified for other species that contain neutral CBZ molecules are absent in all these $\mathrm{Na}$ containing ICC phases and are replaced by $\mathrm{Na}-\mathrm{O}$ dative bonds. However, previously identified nonpolar supramolecular constructs in the form of stacks and dimers are shared with other CBZ containing structures.

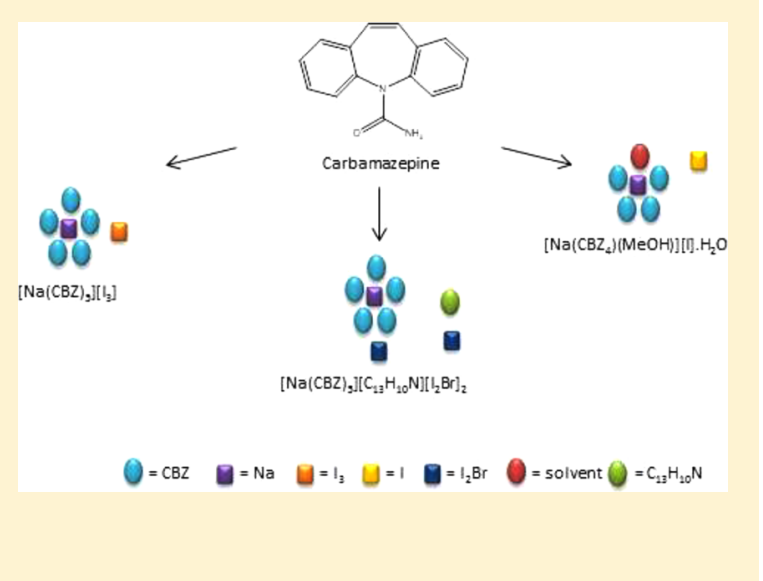

INTRODUCTION

22 Carbemazepine (CBZ) is the anticonvulsant drug used in the 23 treatment of epilepsy that has become one of the best known 24 model compounds used in solid state form identification and 25 characterization studies. It is attractive because it is a 26 molecularly simple active pharmaceutical ingredient (API) 27 with a nonpolar backbone and a single polar amide 28 functionality that is available for hydrogen bonding. Such 29 studies have led to date to five polymorphic crystalline phases 30 of CBZ being described, ${ }^{1-3}$ together with the structures of over 3150 cocrystalline or solvate forms. Approximately half of the 32 crystal coformers used with CBZ are neutral carboxylic acids ${ }^{4-7}$ 33 with organic solvates making up the next biggest grouping. ${ }^{7-10}$ 34 Supramolecular structural similarities throughout these species 35 have been described by Gelbrich and Hursthouse and further 36 commented on by others. ${ }^{4,11}$ Although numerous, most of the 37 known phases of $\mathrm{CBZ}$ are thus somewhat homogeneous with 38 respect to general chemical type. Some alternative formulations 39 have been attempted. For instance, although amide function40 alities are traditionally thought of as being nonionizable under 41 normal chemical conditions, ${ }^{12}$ salt forms of CBZ with 42 protonation at the amide $\mathrm{O}$ atom have recently been reported. 43 Perumalla and Sun described a hydrochloride salt form, ${ }^{13}$ 44 Frampton and co-workers described the methanesulfonate salt 45 form, ${ }^{14}$ and we have described a series of five $[\mathrm{CBZ}(\mathrm{H})][\mathrm{X}]$. $46 n \mathrm{H}_{2} \mathrm{O}(\mathrm{X}=\mathrm{Cl}$ or $\mathrm{Br}, n=0$ or 1$)$ salts. ${ }^{15}$ This latter work also 47 described how exposing carbamazepine hydrochloride to 48 atmospheric water led to the formation of a hydronium salt, $49\left[\mathrm{H}_{3} \mathrm{O}\right][\mathrm{Cl}] \cdot 2 \mathrm{CBZ} \cdot 2 \mathrm{H}_{2} \mathrm{O}$. Although this can be described as a 50 salt form, it contains neutral $\mathrm{CBZ}$ rather than protonated
$\mathrm{CBZ}(\mathrm{H})$ and can thus perhaps be best thought of as a cocrystal 51 of hydronium chloride and CBZ. Recently the term ionic 52 cocrystal (ICC) has been popularized for such formulations to 53 differentiate them from the more usual API cocrystal case 54 where both the coformers are neutral organic molecules. ${ }^{16,17}{ }_{55}$ Structurally similar species with neutral organic molecules 56 cocrystallized with cations and anions are of course well-known 57 in metal coordination chemistry and elsewhere, where they are 58 typically referred to as dipole (or solvent) separated ion pair 59 complexes. $^{18-22}$ Similar species are also known with 60 ammonium ions replacing metal ions. ${ }^{23-25}$ The novelty of 61 the ICC terminology lies in the context of typically 62 pharmaceutically active organic species and the deliberate 63 crystal engineering of their structures to replace organic to 64 organic intermolecular interactions with ionic contacts. Despite 65 the recent coining of the term, such API-based ICC species can 66 be found in the historical literature, including a structural report 67 on two forms of $\mathrm{CBZ}$, namely $\left[\mathrm{NH}_{4}\right][\mathrm{X}][\mathrm{CBZ}]$ where $\mathrm{X}=\mathrm{Cl} 68$ or $\mathrm{Br}^{26}$ With ammonium and hydronium halide complexes of 69 CBZ being known and with the well-known occurrence of 70 donor separated ion pair species throughout main group metal 71 coordination chemistry, we decided to investigate the 72 possibility of forming ICC forms of CBZ with s-block metal 73 salts. Described herein is the synthesis and characterization of 74 three such species, $\left[\mathrm{Na}(\mathrm{CBZ})_{4}(\mathrm{MeOH})\right][\mathrm{I}] \cdot \mathrm{H}_{2} \mathrm{O}, \quad[\mathrm{Na}-75$ $\left.(\mathrm{CBZ})_{5}\right]\left[\mathrm{I}_{3}\right]$, and $\left[\mathrm{Na}(\mathrm{CBZ})_{5}\right]\left[\mathrm{C}_{13} \mathrm{H}_{10} \mathrm{~N}\right]\left[\mathrm{IBr}_{2}\right]_{2}$. 76

Received: September 18, 2014 
Table 1. Selected Crystallographic and Refinement Parameters for Na Complexes

$\begin{array}{ll}\text { compound } & {\left[\mathrm{Na}(\mathrm{CBZ})_{4}(\mathrm{MeOH})\right][\mathrm{I}] \cdot \mathrm{H}_{2} \mathrm{O}} \\ \text { formula } & \mathrm{C}_{61} \mathrm{H}_{54} \mathrm{~N}_{8} \mathrm{NaO}_{6} \\ \text { formula wt } & 1145.01 \\ \text { cryst syst } & \text { monoclinic } \\ \text { space group } & \mathrm{C}_{2} \\ \lambda, \AA & 1.5418 \\ a, \AA & 27.3789(19) \\ b, \AA & 6.8157(2) \\ c, \AA & 20.8598(14) \\ \alpha, \text { deg } & 90 \\ \beta, \text { deg } & 134.626(12) \\ \gamma, \text { deg } & 90 \\ \text { vol, } \AA^{3} & 2770.4(3) \\ \text { temp, K } & 123(2) \\ Z & 2 \\ \text { reflns collected } & 5761 \\ 2 \theta \text { max, deg } & 146.1 \\ \text { reflns unique } & 4078 \\ \text { reflns obsd } & 4037 \\ \text { Rint } & 0.0267 \\ \mathrm{GOF} & 1.078 \\ R[I>2 \sigma(I)], F & 0.0364 \\ R w, F^{2} & 0.0957 \\ \text { max } / \text { min electron density, e } \AA^{-3} & 1.581 /-0.685\end{array}$

\section{EXPERIMENTAL SECTION}

78 Single crystal X-ray diffraction (SXD) measurements on the acridine $79 \mathrm{I}_{2} \mathrm{Br}$ salt were carried out by the National Crystallography Service. ${ }^{27}$ 80 All other crystallographic measurements were performed locally using 81 Oxford Diffraction instruments. Structural solution and refinement 82 against $F^{2}$ to convergence were performed using programs from the 83 SHELX suite. ${ }^{28}$ Hydrogen atoms bound to carbon were placed in 84 idealized positions and refined in riding modes. Where possible, $\mathrm{H}$ 85 atoms bound to nitrogen or oxygen were placed as found in difference 86 Fourier syntheses and refined isotropically but with $\mathrm{N}-\mathrm{H}$ bond length 87 restraints for $\mathrm{CBZ}$ containing species. For the structure of [Na$\left.88(\mathrm{CBZ})_{5}\right]\left[\mathrm{C}_{13} \mathrm{H}_{10} \mathrm{~N}\right]\left[\mathrm{IBr}_{2}\right]_{2}$, poor crystal quality and a disordered CBZ 89 ligand resulted in a relatively low quality structure. Here all $\mathrm{H}$ atoms 90 were generated in idealized positions and allowed to ride on their 91 parent atoms. Selected crystallographic and refinement parameters are 92 given in Table 1 for the Na containing species and in the Supporting 93 Information for the others.

94 FTIR measurements were made on crushed solid samples and with 95 an $\mathrm{A}_{2}$ Technologies ATR instrument.

96 Synthesis of $\left[\mathrm{Na}(\mathrm{CBZ})_{4}(\mathrm{MeOH})\right][\mathrm{I}] \cdot \mathrm{H}_{2} \mathrm{O}$, Method 1. A large 97 excess $(5.010 \mathrm{~g}, 33.4 \mathrm{mmol})$ of sodium iodide and $0.216 \mathrm{~g}(0.91$ $98 \mathrm{mmol}$ ) of carbamazepine were dissolved in $8 \mathrm{~cm}^{3}$ of methanol. The 99 solution was heated in a water bath until the carbamazepine and 100 sodium iodide had dissolved. Once the solution had cooled to room 101 temperature, $1 \mathrm{~cm}^{3}$ of acetyl chloride was slowly added. A vigorous 102 reaction was observed, and NaI precipitated. This was removed by 103 filtration, and the filtrate was poured into a narrow tube and sealed 104 with parafilm. Small holes were made in the parafilm to aid 105 evaporation. Suitable crystals grew after approximately 7 days. IR $106 \nu_{\max } 3458,3323,3266,3197,1652,1575,1490,1418,806,764 \mathrm{~cm}^{-1}$. 107 Synthesis of $\left[\mathrm{Na}(\mathrm{CBZ})_{4}(\mathrm{MeOH})\right][1] \cdot \mathrm{H}_{2} \mathrm{O}$, Method 2. A large 108 excess $(5.306 \mathrm{~g}, 35.4 \mathrm{mmol})$ of sodium iodide and $0.264 \mathrm{~g}(1.12$ $109 \mathrm{mmol}$ ) of carbamazepine were dissolved in $8 \mathrm{~cm}^{3}$ of methanol. The 110 solution was heated in a water bath until both the carbamazepine and 111 sodium iodide had dissolved. The test tube was sealed with parafilm 112 and left to cool to room temperature. Small holes were made in the 113 parafilm to aid evaporation. Suitable crystals grew after approximately 1142 days. SXD and IR spectroscopy showed these to be identical to the 115 product isolated by method 1 .

$\begin{array}{ll}{\left[\mathrm{Na}(\mathrm{CBZ})_{5}\right]\left[\mathrm{I}_{3}\right]} & {\left[\mathrm{Na}(\mathrm{CBZ})_{5}\right]\left[\mathrm{C}_{13} \mathrm{H}_{10} \mathrm{~N}\right]\left[\mathrm{IBr}_{2}\right]_{2}} \\ \mathrm{C}_{75} \mathrm{H}_{60} \mathrm{I}_{3} \mathrm{~N}_{10} \mathrm{NaO}_{5} & \mathrm{C}_{88} \mathrm{H}_{70} \mathrm{Br}_{4} \mathrm{I}_{2} \mathrm{~N}_{11} \mathrm{NaO}_{5} \\ 1585.02 & 1957.98 \\ \text { monoclinic } & \text { triclinic } \\ P 2_{1} / n & P \overline{1} \\ 0.71073 & 0.71073 \\ 16.1230(6) & 10.2171(5) \\ 11.2270(4) & 14.4369(6) \\ 36.8726(16) & 27.5476(12) \\ 90 & 91.841(3) \\ 91.165(3) & 96.689(4) \\ 90 & 90.972(4) \\ 6673.0(4) & 4032.7(3) \\ 153(2) & 123(20) \\ 4 & 2 \\ 32950 & 28299 \\ 54.0 & 50.0 \\ 13309 & 14166 \\ 7205 & 8248 \\ 0.0732 & 0.0708 \\ 1.029 & 1.075 \\ 0.0612 & 0.0847 \\ 0.1019 & 0.2027 \\ 0.646 /-0.750 & 1.351 /-1.168\end{array}$

Synthesis of $\left[\mathrm{Na}\left(\mathrm{CBZ}_{5}\right)\right]\left[\mathrm{I}_{3}\right]$. A large excess $(5.515 \mathrm{~g}, 36.8 \mathrm{mmol}) 116$ of sodium iodide and $0.246 \mathrm{~g}(1.04 \mathrm{mmol})$ of carbamazepine were 117 dissolved in $8 \mathrm{~cm}^{3}$ of ethanol. The solution was heated in a water bath 118 until both the carbamazepine and sodium iodide had dissolved. Once 119 the solution had cooled to room temperature, $1 \mathrm{~cm}^{3}$ of acetyl bromide 120 was slowly added. A vigorous reaction was observed, and an inorganic 121 solid precipitated. This was removed by filtration, and the solution was 122 left in a narrow tube for approximately 1 month, after which time 123 suitable crystals had formed. IR $\nu_{\max } 3463,3434,3411,3266,3194,124$ $1652,1569,1489,1418,1394,808,763 \mathrm{~cm}^{-1}$.

Synthesis of Carbamazepine Ammonium Bromide. Ammo- 12 nium bromide $(0.043 \mathrm{~g}, 0.44 \mathrm{mmol})$ and $0.209 \mathrm{~g}(0.88 \mathrm{mmol})$ of 127 carbamazepine were dissolved in $4 \mathrm{~cm}^{3}$ of methanol. The solution was 128 heated in a water bath until both ammonium bromide and 129 carbamazepine had dissolved. Once the solution had cooled to room 130 temperature, $1 \mathrm{~cm}^{3}$ of acetyl bromide was slowly added. A vigorous 131 reaction was observed. The test tube was sealed with parafilm. Small 132 holes were made in the parafilm to aid evaporation. After 23 days, 133 crystals had formed and were collected for SXD analysis.

Synthesis of Acridinium $\mathrm{I}_{2} \mathrm{X}$ Species, $\left[\mathrm{C}_{13} \mathrm{H}_{10} \mathrm{~N}\right]\left[\mathrm{I}_{2} \mathrm{X}\right], \mathrm{X}=\mathrm{Cl}$ or 135 Br. Potassium iodide $(0.078 \mathrm{~g}, 0.47 \mathrm{mmol})$ and $0.221 \mathrm{~g}(0.94 \mathrm{mmol}) 136$ of carbamazepine were dissolved in $8 \mathrm{~cm}^{3}$ of methanol. The solution 137 was heated in a water bath until both the potassium iodide and 138 carbamazepine had dissolved. Once the solution had cooled to room 139 temperature, $1 \mathrm{~cm}^{3}$ of acetyl chloride was slowly added. A vigorous 140 reaction was observed, and a solid formed, which was removed by 141 filtration. After slow evaporation overnight, colorless crystals of 142 carbamazepine hydrochloride form II were obtained. ${ }^{15}$ Leaving the 143 solution for a further 3 days resulted in darkening of the solution and 144 the deposition of red crystals. These have been characterized as 145 [acridinium] $\left[\mathrm{I}_{2} \mathrm{Cl}\right]$. The same acridinium species was obtained when 146 CsI was used in place of KI. Replacing MI with $\mathrm{NH}_{4} \mathrm{I}$ and using acetyl 147 bromide rather than acetyl chloride gave dark blue crystals of 148 [acridinium] $\left[\mathrm{I}_{2} \mathrm{Br}\right]$.

Synthesis of $\left[\mathrm{Na}(\mathrm{CBZ})_{5}\right]\left[\mathrm{C}_{13} \mathrm{H}_{10} \mathrm{~N}\right]\left[\mathrm{IBr}_{2}\right]_{2}$. Sodium iodide $\left(\begin{array}{lll}0.071 & 150\end{array}\right.$ $\mathrm{g}, 0.43 \mathrm{mmol})$ and $0.224 \mathrm{~g}(0.95 \mathrm{mmol})$ of carbamazepine were 151 dissolved in $4 \mathrm{~cm}^{3}$ of methanol. The solution was heated in a water 152 bath until both sodium iodide and carbamazepine had dissolved. Once 153 the solution had cooled to room temperature, $1 \mathrm{~cm}^{3}$ of hydrobromic 154 acid was added. The test tube was sealed with parafilm. Small holes 155 were made in the parafilm to aid evaporation. Yellow crystalline 156 
157 material was deposited after approximately 4 days. IR $\nu_{\max } 3421,3315$, $1581601,1567,1487,1455,1435,804,769,746,726 \mathrm{~cm}^{-1}$.

\section{RESULTS AND DISCUSSION}

160 The structures of two types of species that can be described as 161 ICC complexes are known for CBZ, the ammonium containing 162 isostructural species $\left[\mathrm{NH}_{4}\right][\mathrm{X}][\mathrm{CBZ}]$ where $\mathrm{X}=\mathrm{Cl}$ or $\mathrm{Br}$ and 163 the hydronium $\left[\mathrm{H}_{3} \mathrm{O}\right][\mathrm{Cl}] \cdot 2 \mathrm{CBZ} \cdot 2 \mathrm{H}_{2} \mathrm{O} .{ }^{15,26}$ Neither type 164 contains a metal ion, so the initial goal of this work was to 165 introduce a pharmaceutically acceptable metal cation such as $166 \mathrm{Na}^{+}$. The known CBZ ICC species were not prepared by 167 straightforward cocrystallization of the salt with CBZ. The 168 ammonium species were prepared by Reck and Thiel in the 169 presence of a surfactant, ${ }^{26}$ while the hydronium species 170 originated from slow addition of atmospheric water to a 171 reactive salt form of $\mathrm{CBZ}$, namely, the oxygen protonated salt $172[\mathrm{CBZ}(\mathrm{H})][\mathrm{Cl}] .{ }^{15}$ Initially, we attempted to form CBZ ICC 173 complexes by simply cocrystallizing methanolic solutions of $174 \mathrm{CBZ}$ with aqueous solutions of a wide variety of simple s-block 175 metal salts. None of these attempts were successful; nor was a 176 similar attempt to prepare $\left[\mathrm{NH}_{4}\right][\mathrm{X}][\mathrm{CBZ}]$ in the absence of 177 surfactant. It was thus decided to attempt an adaptation of the 178 route that gave the hydronium species. This involved addition 179 of acetyl halide to methanol solutions of the API to give in situ 180 generation of nonaqueous $\mathrm{HCl}$ or $\mathrm{HBr}$. In the absence of other 181 ions, this is known to give protonated CBZ, which crystallizes 182 as halide salts. ${ }^{13,15}$ However, herein the methanolic CBZ 183 solutions also contained additional simple salts (usually iodides 184 because these were found to be more soluble than other 185 halides) initially in very high concentrations in an attempt to 186 force the inclusion of ions in the final product. This approach 187 allowed the isolation of two ICC forms of CBZ with Na. Single 188 crystal diffraction showed these to be $\left[\mathrm{Na}(\mathrm{CBZ})_{4}(\mathrm{MeOH})\right][\mathrm{I}]$. $189 \mathrm{H}_{2} \mathrm{O}$ and $\left[\mathrm{Na}(\mathrm{CBZ})_{5}\right]\left[\mathrm{I}_{3}\right]$, see Experimental Section for 190 preparative details. Despite the great efforts previously 191 expended on preparing novel forms of CBZ, there are no 192 structural reports of CBZ species that contain metal ions in the 193 CCDC. $^{29}$ A similar approach utilizing acetyl bromide also 194 allowed $\left[\mathrm{NH}_{4}\right][\mathrm{Br}][\mathrm{CBZ}]$ to be isolated and analyzed without 195 the use of surfactant.

196 The structure of $\left[\mathrm{Na}(\mathrm{CBZ})_{4}(\mathrm{MeOH})\right][\mathrm{I}] \cdot \mathrm{H}_{2} \mathrm{O}$ has crystallo197 graphically imposed $C_{2}$ symmetry, and both [Na$\left.198(\mathrm{CBZ})_{4}(\mathrm{MeOH})\right][\mathrm{I}] \cdot \mathrm{H}_{2} \mathrm{O}$ and $\left[\mathrm{Na}(\mathrm{CBZ})_{5}\right]\left[\mathrm{I}_{3}\right]$ feature dis199 torted square pyramidal $\mathrm{NaO}_{5}$ cores $(\tau=0.41$ and 0.28 for $200\left[\mathrm{Na}(\mathrm{CBZ})_{4}(\mathrm{MeOH})\right][\mathrm{I}] \cdot \mathrm{H}_{2} \mathrm{O}$ and $\left[\mathrm{Na}(\mathrm{CBZ})_{5}\right]\left[\mathrm{I}_{3}\right]$, respec201 tively, where $\tau=0$ indicates ideal square pyramidal geometry 202 and $\tau=1$ corresponds to trigonal bipyramidal), ${ }^{30}$ see Figures 1 203 and 2 . In both cases, the $\mathrm{Na}$ ion is raised slightly above the basal 204 plane described by the four $\mathrm{O}$ donor atoms from the $\mathrm{CBZ}$ 205 ligands (by $0.453(3)$ and $0.574(3) \AA$, respectively), with the 206 apical coordination site being occupied by a disordered $\mathrm{MeOH}$ 207 ligand in $\left[\mathrm{Na}(\mathrm{CBZ})_{4}(\mathrm{MeOH})\right][\mathrm{I}] \cdot \mathrm{H}_{2} \mathrm{O}$ and by a fifth $\mathrm{CBZ}$ 208 ligand in $\left[\mathrm{Na}(\mathrm{CBZ})_{5}\right]\left[\mathrm{I}_{3}\right] . \mathrm{Na}-\mathrm{O}$ bond lengths in the more 209 sterically crowded $\left[\mathrm{Na}(\mathrm{CBZ})_{5}\right]$ cation are somewhat elongated 210 compared with those of the $\left[\mathrm{Na}(\mathrm{CBZ})_{4}(\mathrm{MeOH})\right]$ ion. The 211 range of basal $\mathrm{Na}-\mathrm{O}$ distances is thus 2.326(4) to 2.403(4) $\AA$ 212 for $\left[\mathrm{Na}(\mathrm{CBZ})_{5}\right]$ and $2.317(3)$ to $2.366(3) \AA$ for $[\mathrm{Na}-$ $\left.213(\mathrm{CBZ})_{4}(\mathrm{MeOH})\right]$. In both species, the apical $\mathrm{Na}-\mathrm{O}$ bond is 214 the shortest, with this being a more significant difference for the 215 coordinated $\mathrm{MeOH}\left(2.307(4)\right.$ and 2.258(9) $\AA$ for $\left[\mathrm{Na}(\mathrm{CBZ})_{5}\right]$ 216 and $\left[\mathrm{Na}(\mathrm{CBZ})_{4}(\mathrm{MeOH})\right]$, respectively). All four CBZ ligands 217 of the $\left[\mathrm{Na}(\mathrm{CBZ})_{4}(\mathrm{MeOH})\right]$ ion are orientated so that their 218 azepine rings lie below the complex's basal plane, with one trans

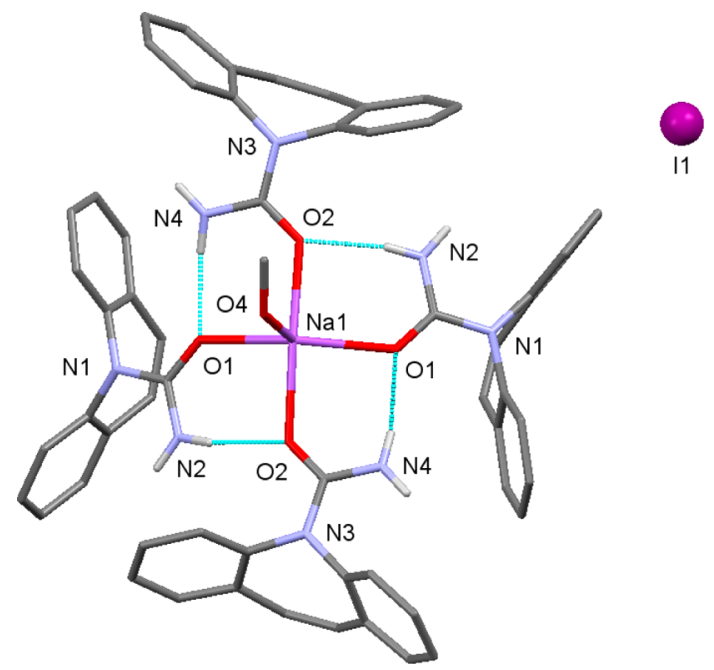

Figure 1. Molecular structure of $\left[\mathrm{Na}(\mathrm{CBZ})_{4}(\mathrm{MeOH})\right][\mathrm{I}] \cdot \mathrm{H}_{2} \mathrm{O}$. Disorder in the solvent and all nonamide hydrogen atoms have been omitted for clarity. Here and elsewhere, hydrogen bonds are shown as light blue lines.

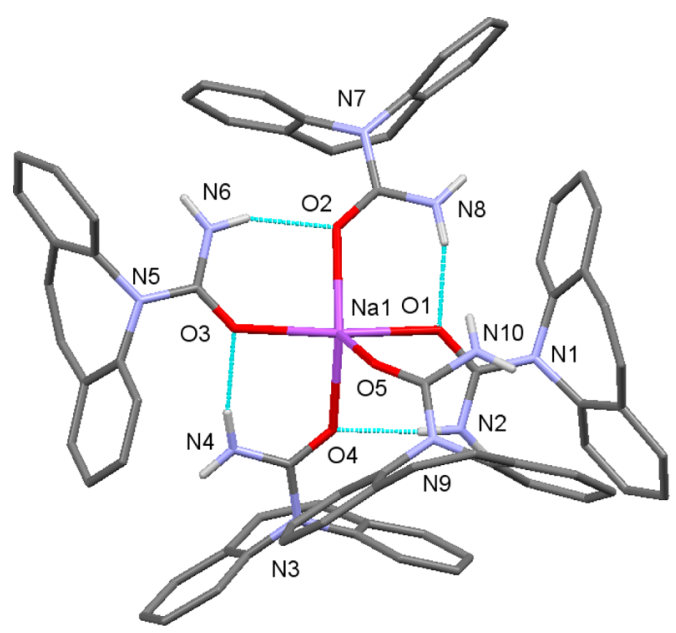

Figure 2. Molecular structure of the cation in $\left[\mathrm{Na}(\mathrm{CBZ})_{5}\right]\left[\mathrm{I}_{3}\right]$. Nonamide hydrogen atoms have been omitted for clarity.

pair of ligands significantly more below the plane than the other 219 mutually trans pair (compare $145.33(19)^{\circ}$ and $170.0(2)^{\circ}$ for 220 $\mathrm{O} 1-\mathrm{Na} 1-\mathrm{O} 1^{\prime}$ and $\mathrm{O} 2-\mathrm{Na} 1-\mathrm{O} 2^{\prime}$ respectively, ${ }^{\prime}=1-x, y, 1221$ $-z)$.

222

The four basal CBZ ligands of the $\left[\mathrm{Na}(\mathrm{CBZ})_{5}\right]$ ion adopt a 223 different conformation, with three azepine rings below the basal 224 plane and one (that containing N1) above the plane, see Figure $225 \mathrm{f} 3$ 3. Despite this conformational difference, intramolecular $226 \mathrm{f} 3$ hydrogen bonding between the four basal CBZ ligands is 227 similar for the two complexes, Figures 1 and 2. In each 228 complex, each of the amide $\mathrm{NH}_{2}$ groups of the four basal CBZ 229 ligands donates a single intramolecular hydrogen bond to the 230 amide $\mathrm{O}$ atom acceptor of the neighboring basal CBZ ligand. 231 The second $\mathrm{H}$ atom of these four $\mathrm{NH}_{2}$ groups does not form a 232 hydrogen bonding interaction. The apical CBZ ligand of the 233 $\left[\mathrm{Na}(\mathrm{CBZ})_{5}\right]$ cation does not take part in any classical hydrogen 234 bonds, but its $\mathrm{NH}_{2}$ group is orientated toward the olefin 235 backbone of the unique azepine ring that lies above the basal 236 plane ( $\mathrm{H}$ to $\mathrm{C}=\mathrm{C}$ centroid is $2.80 \AA$ ). In contrast, the apical 237 $\mathrm{MeOH}$ ligand of $\left[\mathrm{Na}(\mathrm{CBZ})_{4}(\mathrm{MeOH})\right]$ simply donates a O- 238 


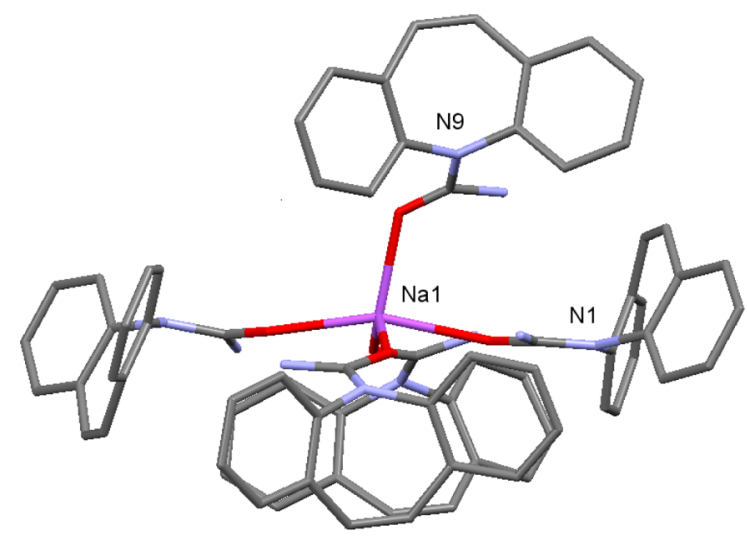

Figure 3. Cation of $\left[\mathrm{Na}(\mathrm{CBZ})_{5}\right]\left[\mathrm{I}_{3}\right]$ drawn so as to emphasize the three down, one up conformation of the apezine rings of the four basal ligands. The ligand containing N9 is the fifth, apical ligand.

$239 \mathrm{H} \cdots \mathrm{O}$ hydrogen bond to the water solvate. Both $\mathrm{MeOH}$ and 240 water positions are disordered about the crystallographic 2-fold 241 rotation axis, and thus discussion of the geometric details of 242 these groups is not warranted. This difference in hydrogen 243 bonding between the two species may contribute to the 244 different conformations of the basal $\mathrm{Na}(\mathrm{CBZ})_{4}$ units. 245 Examination of the bond lengths of the amide groups and 246 comparison with literature compilations of equivalent data 247 shows that all the CBZ ligands of these two Na complexes have $248 \mathrm{C}=\mathrm{O}$ and $\mathrm{C}-\mathrm{N}$ bond lengths that lie within the ranges 249 normally seen for neutral CBZ species. ${ }^{14,15}$ This indicates that 250 complexation to $\mathrm{Na}$ does not greatly alter the ligands' internal 251 geometries. However, the geometry of the apical CBZ ligand of 252 the $\left[\mathrm{Na}(\mathrm{CBZ})_{5}\right]$ cation does differ subtly from the geometries 253 of the other coordinated CBZ ligands. The $\mathrm{C}=\mathrm{O}$ length of the 254 apical ligand is somewhat shorter than the others (compare $2551.223(7)$ with a range of $1.240(6)-1.251(6) \AA$ ) and both $\mathrm{C}-\mathrm{N}$ 256 distances of the apical ligand are somewhat longer than those of 257 the other ligands (compare 1.370(8) and 1.378(7) $\AA$ for C$258 \mathrm{NH}_{2}$ and $\mathrm{C}-\mathrm{NR}_{2}$ with ranges of $1.335(7)-1.344(8)$ and $2591.354(7)-1.369(7) \AA$ ).

260 Most of the cocrystallization experiments attempted simply 261 returned the starting materials or CBZ dihydrate or previously 262 known hydrogen halide salts of $\mathrm{CBZ}$ as the sole products. The 263 color of some experiments, especially those with low $\mathrm{pH}$, was 264 observed to darken with time. Similar darkening of samples 265 with time was seen in solutions of protonated $\mathrm{CBZ}(\mathrm{H})$ salt 266 forms. ${ }^{15}$ This was attributed to the decomposition of CBZ to 267 acridine, and this is now confirmed by the isolation and crystal 268 structure determination of two acridinium salt species, $269\left[\mathrm{C}_{13} \mathrm{H}_{10} \mathrm{~N}\right]\left[\mathrm{I}_{2} \mathrm{X}\right], \mathrm{X}=\mathrm{Cl}$ or $\mathrm{Br}$. The structures are included in 270 the Supporting Information as rare examples of crystallo271 graphically well ordered $\left[\mathrm{I}_{2} \mathrm{X}\right]_{n}$ species. $^{31-33}$ Although the 272 transformation from CBZ to acridine is rather unintuitive, a 273 variety of experimental conditions have been reported to induce 274 this decomposition. Indeed acridine is a known metabolite of 275 CBZ. ${ }^{34-37}$ On attempting to replace in situ generation of acid 276 with a simple addition of aqueous $\mathrm{HBr}$, a third $\mathrm{Na}$ ICC 277 complex was obtained, $\left[\mathrm{Na}(\mathrm{CBZ})_{5}\right]\left[\mathrm{C}_{13} \mathrm{H}_{10} \mathrm{~N}\right]\left[\mathrm{IBr}_{2}\right]_{2}$. That 278 this species contains both CBZ and acridinium makes it of 279 enhanced interest, see Figure 4.

280 The $\left[\mathrm{Na}(\mathrm{CBZ})_{5}\right]$ cation in $\left[\mathrm{Na}(\mathrm{CBZ})_{5}\right]\left[\mathrm{C}_{13} \mathrm{H}_{10} \mathrm{~N}\right]\left[\mathrm{IBr}_{2}\right]_{2}$ is 281 similar to that in $\left[\mathrm{Na}(\mathrm{CBZ})_{5}\right]\left[\mathrm{I}_{3}\right]$ in that the $\mathrm{NaO}_{5}$ core has a 282 near square pyramidal geometry $(\tau=0.11, \mathrm{Na} 1$ raised $0.395(5)$ $283 \AA$ from the plane defined by the four basal O atoms). Another

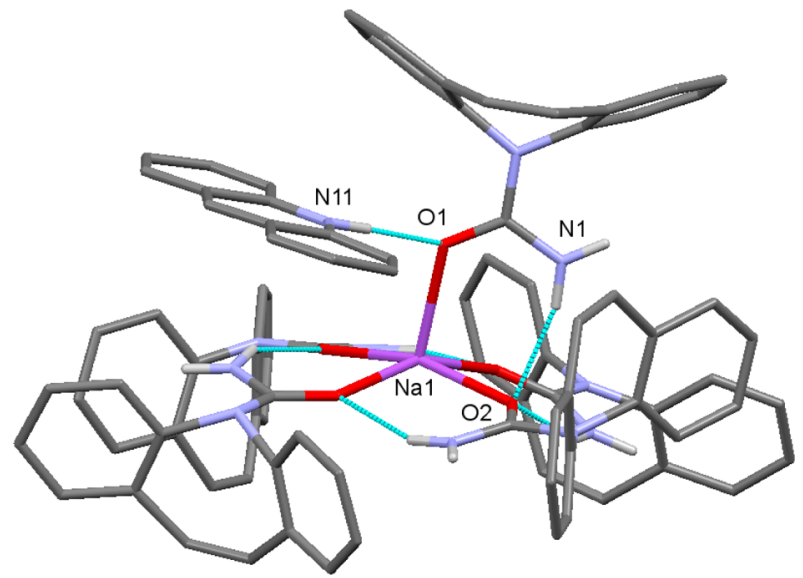

Figure 4. Hydrogen bonded $\left[\mathrm{Na}(\mathrm{CBZ})_{5}\right]$ and acridinium cation pair found in the structure of $\left[\mathrm{Na}(\mathrm{CBZ})_{5}\right]\left[\mathrm{C}_{13} \mathrm{H}_{10} \mathrm{~N}\right]\left[\mathrm{IBr}_{2}\right]_{2} . \mathrm{H}$ atoms bound to $\mathrm{C}$ are omitted for clarity.

similarity is that one of the four basal CBZ ligands is again 284 orientated with its azepine ring above the basal plane defined by 285 the four $\mathrm{O}$ atoms and the other three azepine rings lie below 286 this plane. However, one of these basal CBZ ligands is 287 disordered such that a minor conformation is also present in 288 the crystal, and this has two azepine rings above the basal plane 289 and two below it. As with both the other $\mathrm{Na}$ complexes, the 290 amide groups of the four basal CBZ ligands form intra- 291 molecular $\mathrm{N}-\mathrm{H} \cdots \mathrm{O}$ hydrogen bonds with their neighboring 292 CBZ ligands. The $\mathrm{NH}_{2}$ group of the fifth apical CBZ ligand 293 behaves differently from that in $\left[\mathrm{Na}(\mathrm{CBZ})_{5}\right]\left[\mathrm{I}_{3}\right]$. Rather than a 294 weak interaction with the $\pi$ system of the azepine ring that is 295 raised above the basal plane, here the amine group forms a 296 classical $\mathrm{N}-\mathrm{H} \cdots \mathrm{O}$ interaction with the $\mathrm{O}$ atom of the raised 297 ligand. Meanwhile, the $\mathrm{O}$ atom of the apical CBZ ligand is 298 involved in a strong hydrogen bond with the formally positively 299 charged $\mathrm{N}-\mathrm{H}$ group of the acridinium cation. Thus, the two 300 cations $\left[\mathrm{Na}(\mathrm{CBZ})_{5}\right]$ and $\left[\mathrm{C}_{13} \mathrm{H}_{10} \mathrm{~N}\right]$ are bound tightly together. 301 None of the anions in any of the three $\mathrm{Na}$ species described 302 interact with polar groups of the cations. In all cases, only C -303 $\mathrm{H} \cdots \mathrm{X} \quad(\mathrm{X}=\mathrm{I}$ or $\mathrm{Br})$ interactions are observed. For 304 $\left[\mathrm{Na}(\mathrm{CBZ})_{5}\right]\left[\mathrm{I}_{3}\right]$ none of these interactions are shorter than 305 the sum of van der Waals distances while the other two species 306 each make four $\mathrm{C}-\mathrm{H} \cdots \mathrm{X}$ interactions shorter than van der 307 Waals distances. Inorganic coordination chemists would thus 308 classify all three species as dipole separated ion pair 309 complexes. $^{18-22}$

310

ICC forms are of generic interest because they present the 311 possibility of generating API containing materials with different 312 intermolecular bond types from those seen in organic systems, 313 and this may allow the chemicophysical properties of APIs to 314 be modified. ${ }^{16,17}$ Intermolecular interactions and packing in 315 CBZ polymorphs and cocrystals have been widely commented 316 on in the literature. Two descriptive strands are often used. The 317 first of these describes the various supramolecular synthons 318 found in CBZ species, commonly such synthons are based on 319 the hydrogen bonding modes of the amide group. The various 320 structures of the CBZ polymorphs are based upon CBZ dimers. 321 This dimeric arrangement is often contrasted with a theoretical 322 chain structure predicted to be stable and similar to the motif 323 found in related amides. ${ }^{38-41}$ In many cocrystalline forms of 324 CBZ, the dimeric motif is retained, commonly with the addition 325 of $\mathrm{N}-\mathrm{H} \cdots \mathrm{A}$ hydrogen bonds as shown in Figure 5. An $326 \mathrm{fs}$ 


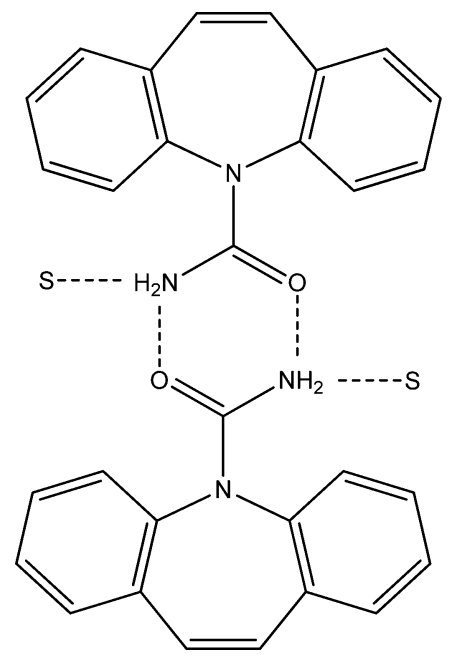

Figure 5. Representation of the CBZ hydrogen bonded dimer motif. When present, $S$ is a hydrogen bond acceptor in the form of a solvent molecule or a cocrystal conformer.

327 alternative arrangement is found in phases where the coformer 328 is a carboxylic acid. Here the commonly found motif is a 329 heterodimer with an amide to $\mathrm{COOH}$ contact. ${ }^{8,9}$ A second 330 strand of CBZ structural analysis has looked not just at 331 intermolecular bonding interactions but at supramolecular 332 constructs, that is at any packing motif that is repeated in 333 different CBZ phases no matter what the bonding nature of the 334 interaction might be. This approach identified two dimeric 335 constructs and two stacking constructs that appear in multiple $336 \mathrm{CBZ}$ structures (including the hydrogen bonded dimer 337 discussed above). ${ }^{11}$

338 Ammonium halide based ICC forms of CBZ have been 339 known for some time. These are the isostructural species $340\left[\mathrm{NH}_{4}\right][\mathrm{X}][\mathrm{CBZ}]$ where $\mathrm{X}=\mathrm{Cl}$ and $\mathrm{Br}^{26}$ Because the available 341 database structures (VUBCAW and VUBCEA) do not contain 342 information on $\mathrm{H}$ atom positions, we have redetermined the 343 structure of $\left[\mathrm{NH}_{4}\right][\mathrm{Br}][\mathrm{CBZ}]$ at low temperature. This 344 confirms that $\left[\mathrm{NH}_{4}\right][\mathrm{Br}][\mathrm{CBZ}]$ has a $\mathrm{CBZ}$ hydrogen bonded 345 dimer motif with further hydrogen bonds from the dimer to 346 both cations and anions, see Figure 6 . This is a simple variation 347 on the hydrogen bonding structure common to many organic

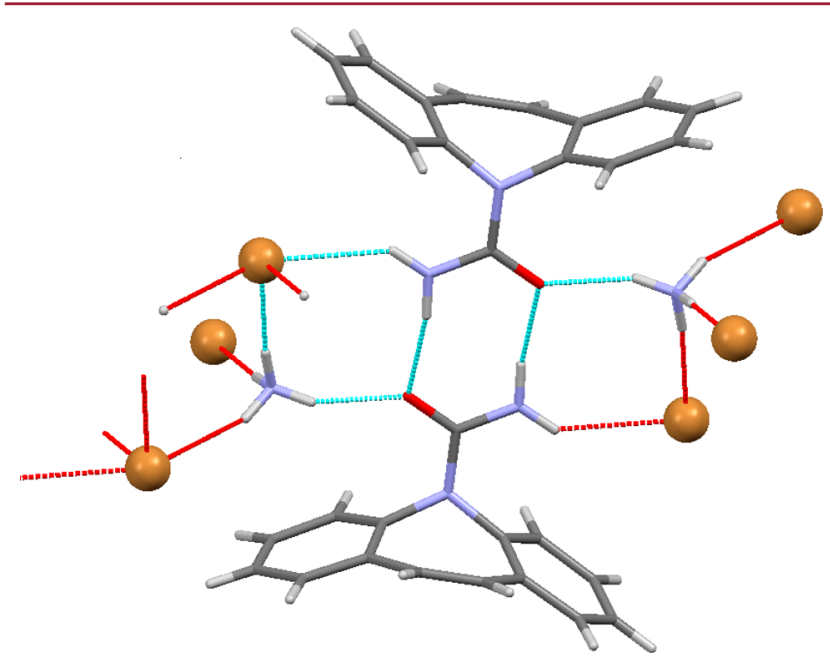

Figure 6. Part of the hydrogen bonding motif found in the structure of $\left[\mathrm{NH}_{4}\right][\mathrm{Br}][\mathrm{CBZ}]$. Bromide ions drawn as brown spheres. cocrystals of CBZ. The hydronium, $\left[\mathrm{H}_{3} \mathrm{O}\right][\mathrm{Cl}] \cdot 2 \mathrm{CBZ} \cdot 2 \mathrm{H}_{2} \mathrm{O}, 348$ also retains the hydrogen bonded CBZ dimer although CBZ 349 salt forms with $\mathrm{O}$ atom protonated amide groups do not. ${ }^{15} 350$ Furthermore, the $\left[\mathrm{NH}_{4}\right][\mathrm{X}][\mathrm{CBZ}]$ species were included in 351 Gelbrich and Hursthouse's initial work on supramolecular 352 constructs in CBZ. ${ }^{11}$ In this analysis, both have entirely 353 unexceptional packing features with structures that contain the 354 common "translational stack" motif as well as the hydrogen 355 bonded dimer (supramolecular constructs A and C in ref 11). 356 Thus, despite containing charged ions, the ICC structures of 357 $\left[\mathrm{NH}_{4}\right][\mathrm{X}][\mathrm{CBZ}]$ are not obviously different from the 358 structures of nonionic CBZ cocrystals. However, the three $\mathrm{Na} 359$ containing ICC forms of CBZ described herein do have 360 significant structural differences from the CBZ cocrystals 361 previously described. The hydrogen bonded CBZ dimer is 362 now absent. Complexation to the $\mathrm{Na}$ center requires the $\mathrm{CBZ} 363$ ligands to point inward to the common center and constrains 364

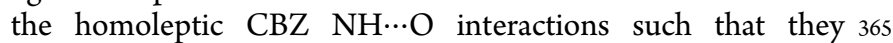
connect only to CBZ ligands bound to the shared Na center. 366 Note that although the observed structures do not contain CBZ 367 dimers, such an arrangement is entirely possible. The structures 368 of ammonium and alkali metal salts of the same anions are 369 often isostructural; ${ }^{42-45}$ thus a situation where the "NaI" 370 species adopt structures akin to that of $\left[\mathrm{NH}_{4}\right][\mathrm{Br}][\mathrm{CBZ}]$ is 371 conceivable. Although the three $\mathrm{Na}$ complexes do not adopt the 372 same hydrogen bonded supramolecular synthons as other CBZ 373 species, they do adopt the nonpolar (or shape-based) 374 supramolecular constructs previously identified. ${ }^{11}$ Both trans- 375 lational stacks and dimeric examples can be identified, as 376 illustrated in Figures 7 and 8.
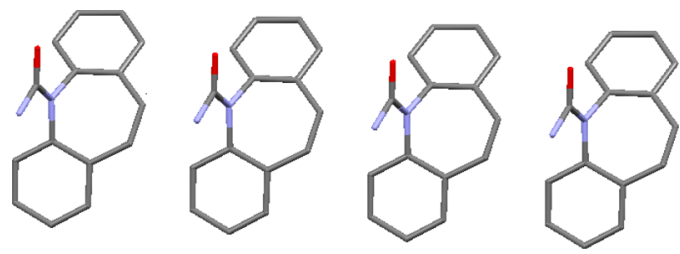

Figure 7. Translational stack of $\mathrm{CBZ}$ molecules found in the structure of $\left[\mathrm{Na}(\mathrm{CBZ})_{4}(\mathrm{MeOH})\right][\mathrm{I}] \cdot \mathrm{H}_{2} \mathrm{O}$. This is supramolecular construct $\mathrm{A}$ in ref 11 . In this case, the translation is along the crystallographic $b$ axis and hence along the $\mathrm{Na}-\mathrm{O}(\mathrm{MeOH})$ molecular axis.

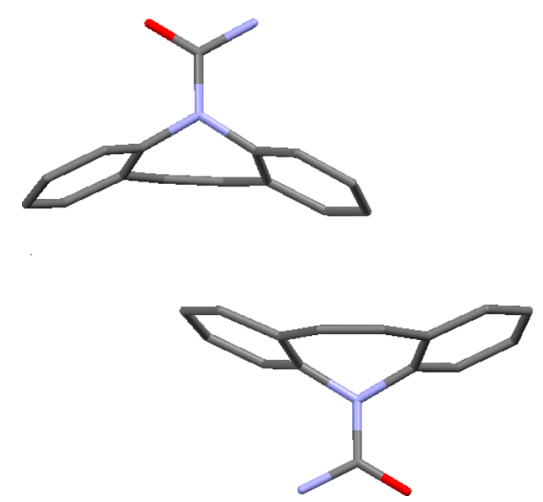

Figure 8. Close packed dimer of $\mathrm{CBZ}$ molecules found in the structure of $[\mathrm{Na}(\mathrm{CBZ})]\left[\mathrm{I}_{3}\right]$. This is supramolecular construct $\mathrm{B}$ in ref 11 . Similar interactions can be found in the structure of $\left[\mathrm{Na}(\mathrm{CBZ})_{5}\right]$ $\left[\mathrm{C}_{13} \mathrm{H}_{10} \mathrm{~N}\right]\left[\mathrm{IBr}_{2}\right]_{2}$. 


\section{CONCLUSION}

379 The first structures of metal containing forms of CBZ have 380 been synthesized and crystallographically characterized. These 381 three $\mathrm{Na}$ complexes can be described as ionic cocrystals. 382 Synthesis at low $\mathrm{pH}$ was found to be advantageous. Unlike the 383 previously described ammonium halide and hydronium 384 chloride ICC forms of CBZ, these new structures do not 385 show the same intermolecular bonding motifs as other neutral$386 \mathrm{CBZ}$ containing phases. Instead dative bonds between $\mathrm{Na}$ and 387 the $\mathrm{O}$ atom of $\mathrm{CBZ}$ predominate and, because the halide based 388 anions make only relatively weak $\mathrm{C}-\mathrm{H} \cdots \mathrm{X}$ contacts with the 389 cations, give dipole separated ion pair forms. CBZ to CBZ 390 hydrogen bonding interactions exist solely within the ligand 391 sets of single $\left[\mathrm{Na}(\mathrm{CBZ})_{4}(\mathrm{HOMe})\right]$ or $\left[\mathrm{Na}(\mathrm{CBZ})_{5}\right]$ cations. 392 Despite the dramatic change in intermolecular bond type and 393 geometry, the three $\mathrm{Na}$ containing CBZ ICC phases still 394 present the previously identified nonpolar CBZ supramolecular 395 constructs, showing that here at least these shape-based packing 396 motifs are more robust than the polar hydrogen bonded 397 synthons. The change in intermolecular bonding and the high 398 ratio of CBZ to coformer make these ICC forms interesting 399 materials for the study of API form selection.

\section{$400 \quad$ ASSOCIATED CONTENT}

\section{S Supporting Information}

$402 \mathrm{X}$-ray crystallographic information for $\left[\mathrm{NH}_{4}\right][\mathrm{Br}][\mathrm{CBZ}]$ and 403 the acridinium salts with $\mathrm{I}_{2} \mathrm{Br}$ and $\mathrm{I}_{2} \mathrm{Cl}$ and crystallographic 404 information files (CIF) for all six structures. This material is 405 available free of charge via the Internet at http://pubs.acs.org. 406 Crystallographic information files are also available from the 407 Cambridge Crystallographic Data Center (CCDC) upon 408 request (http://www.ccdc.cam.ac.uk, CCDC deposition num409 bers 1023495 to 1023500 ).

\section{AUTHOR INFORMATION}

\section{Corresponding Author}

412 *a.r.kennedy@strath.ac.uk.

\section{Notes}

414 The authors declare no competing financial interest.

\section{ACKNOWLEDGMENTS}

416 The authors thank the National Crystallography Service at the 417 University of Southampton for data collection on the $\mathrm{I}_{2} \mathrm{Br}$ salt 418 of acridinium.

\section{$419 \square$ REFERENCES}

420 (1) Arlin, J.-B.; Price, L. S.; Price, S. L.; Florence, A. J. Chem. 421 Commun. 2011, 47, 7074.

422 (2) Lang, M.; Kampf, J. W.; Matzger, A. J. J. Pharm. Sci. 2002, 91, 4231186 .

424 (3) Grzesiak, A. L.; Lang, M.; Kim, K.; Matzger, A. J. J. Pharm. Sci. 425 2003, 92, 2260.

426 (4) Childs, S. L.; Wood, P. A.; Rodriguez-Hornedo, N.; Reddy, L. S.; 427 Hardcastle, K. I. Crystal Growth Des. 2009, 9, 1869.

428 (5) Majumder, M.; Buckton, G.; Rawlinson-Malone, C.; Williams, A. 429 C.; Spillman, M. J.; Shankland, N.; Shankland, K. CrystEngComm 2011, $43013,6327$.

431 (6) Childs, S. L.; Rodriguez-Hornedo, N.; Reddy, L. S.; Jayasanker, 432 A.; Maheshwari, C.; McCausland, L.; Shipplett, R.; Stahly, B. C. 433 CrystEngComm 2008, 10, 856.

434 (7) Fleischman, S. G.; Kuduva, S. S.; McMahon, J. A.; Moulton, B.; 435 Bailey Walsh, R. D.; Rodriquez-Hornedo, N.; Zaworotko, M. J. Crystal 436 Growth Des. 2003, 3, 909.
(8) Johnston, A.; Johnston, B. F.; Kennedy, A. R.; Florence, A. J. 437 CrystEngComm 2008, 10, 23.

(9) Florence, A. J.; Johnston, A.; Price, S. L.; Nowell, H.; Kennedy, A. 439 R.; Shankland, N. J. Pharm. Sci. 2006, 95, 1918.

(10) Fabbiani, F. P. A.; Byrne, L. T.; McKinnon, J. J.; Spackman, M. 441 A. CrystEngComm 2007, 9, 728.

(11) Gelbrich, T.; Hursthouse, M. B. CrystEngComm 2006, 8, 448.443

(12) Nanubolu, J. B.; Sridhar, B.; Ravikumar, K. CrystEngComm 444 2012, 14, 2571.

(13) Perumalla, S. R; Sun, C. C. Chem.-Eur. J. 2012, 18, 6462.446

(14) Eberlin, A. R.; Eddleston, M. D.; Frampton, C. S. Acta 447 Crystallogr. 2013, C69, 1260.

(15) Buist, A. R.; Kennedy, A. R.; Shankland, K.; Shankland, N.; 449 Spillman, M. J. Cryst. Growth Des. 2013, 13, 5121.

(16) Braga, D.; Grepioni, F.; Maini, L.; Capucci, D.; Nanna, S.; 451 Wouters, J.; Aerts, L.; Quéré, L. Chem. Commun. 2012, 48, 8219.

(17) Braga, D.; Grepioni, F.; Maini, L.; Prosperi, S.; Gobetto, R.; 453 Chierotti, M. R. Chem. Commun. 2010, 46, 7715.

(18) Belsky, V. K.; Masiennikova, V. I. Acta Crystallogr. 1999, C55, 455 No. 9900057.

(19) Chessa, S.; Wright, J. A. Acta Crystallogr. 2007, E63, No. m787. 457

(20) Hevia, E.; Chua, J. Z.; Garcia-Alvarez, P.; Kennedy, A. R.; 458 McCall, M. D. Proc. Natl. Acad. Sci. U.S.A. 2010, 107, 5294.

(21) Blair, V. L.; Clegg, W.; Kennedy, A. R.; Livingstone, Z.; Russo, 460 L.; Hevia, E. Angew. Chem., Int. Ed. 2011, 50, 9857.

(22) Wong, K. C.; Hamid, A.; Baharuddin, S.; Quah, C. K.; Fun, H.- 462 K. Acta Crystallogr. 2009, E65, No. m1308. 463

(23) Bandy, J. A.; Kennard, C. H. L.; Parsons, D. G.; Truter, M. R. J. 464 Chem. Soc., Perkin Trans. II 1984, 309.

(24) Chekhlov, A. N. Russ. J. Inorg. Chem. 2010, 55, 435.

(25) Metz, B.; Rosalky, J. M.; Weiss, R. Chem. Commun. 1976, 533. 467

(26) Reck, G.; Thiel, W. Pharmazie 1991, 46, 509.

(27) Cole, S. J.; Gale, P. A. Chem. Sci. 2012, 3, 683.

(28) Sheldrick, G. M. Acta Crystallogr. 2008, A64, 112.

(29) Allen, F. H. Acta Crystallogr. 2002, B58, 380.

(30) Addison, A. W.; Rao, T. N. J. Chem. Soc., Dalton Trans. 1984, 7, 472 1349.

(31) Chernovyants, M. S.; Burykin, I. V.; Kostrub, V. V.; Tsupak, E. 474 B.; Starikova, Z. A.; Kirsanova, J. A. J. Mol. Struct. 2012, 1010, 98.475

(32) Shilov, G. V.; Kazheva, O. N.; Dyachenko, O. A.; Chernovyants, 476 M. S.; Simonyan, S. S.; Goleva, V. E.; Pyshchev, A. I. Russ. J. Phys. 477 Chem. 2002, 76, 1436.

(33) Wang, Y.-Q.; Wang, Z.-M.; Liao, C.-S.; Yan, C.-H. Acta 479 Crystallogr. 1999, C55, 1503.

(34) Csetenyi, J.; Baker, K. M.; Frigerio, A. J. Pharm. Pharmaci. 1973, 481 25,340 .

(35) Miao, X.-S.; Metcalfe, C. D. Anal. Chem. 2003, 75, 3731.

(36) Furst, S. M.; Uetrecht, J. P. Biochem. Pharmacol. 1993, 45, 1267. 484

(37) Jelic, A.; Cruz-Morató, C.; Marco-Urrea, E.; Sarrá, M.; Perez, S.; 485 Vincent, T.; Petrović, M.; Barcela, D. Water Res. 2012, 46, 955.

(38) Florence, A. J.; Leech, C. K.; Shankland, N.; Shankland, K.; 487 Johnson, A. CrystEngComm 2006, 8, 746.

(39) Arlin, J.-B.; Johnston, A.; Miller, G. J.; Kennedy, A. R.; Price, S. 489 L.; Florence, A. J. CrystEngComm 2010, 12, 64.

(40) Florence, A. J.; Bedford, C. T.; Fabbiani, F. P. A.; Shankland, K.; 491 Gelbrich, T.; Hursthouse, M. B.; Shankland, N.; Johnston, A.; 492 Fernandes, P. CrystEngComm 2008, 10, 811.

(41) Cruz Cabeza, A. J.; Day, G. M.; Motherwell, W. D. S.; Jones, W. 494 Crystal Growth Des. 2007, 7, 100.

(42) Whiteside, A.; Xantheas, S. S.; Gutowski, M. Chem.-Eur. J. 496 2011, 17, 13197.

(43) Ktari, L.; Abdelhedi, M.; Dammak, M.; Cousson, A.; Kolsi, A. 498 Acta Crystallogr. 2008, E64, i18. (44) Leban, I.; Rudan-Tasic, D.; Lah, N.; Klofutar, C. Acta Crystallogr. 500 2007, B63, 418.

(45) Gelbrich, T.; Threlfall, T. L.; Huth, S.; Seeger, E.; Hursthouse, 502 M. B. Z. Anorg. Allg. Chem. 2004, 630, 1451. 